\title{
ЭФФЕКТИВНОСТЬ СКАРМЛИВАНИЯ ТЕЛЯТАМ ЭНЕРГЕТИЧЕСКОЙ КОРМОВОЙ ДОБАВКИ «ЦЕОЛФАТ» В СОСТАВЕ КОМБИКОРМА
}

\section{A.R. Kashaeva, Sh.K. Shakirov, F.K. Akhmetzyanova, E.O. Krupin \\ THE EFFICIENCY OF FEEDING CALVES WITH THE ENERGY FODDER ADDITIVE "ZEOLFAT" IN FEED COMPOSITION}

Кашаева Алия Ринатовна - канд. биол. наук, доц. каф. кормления Казанской государственной академии ветеринарной медицины им. Н.Э. Баумана, г. Казань. E-mail: aliam_81@mail.ru

Шакиров Шамиль Касымович - д-р с.-х. наук, профр., гл. науч. сотр. отдела агробиологических исследований Татарского НИИ сельского хозяйства - обособленного структурного подразделения ФИЦ «КазНЦ РАН», г. Казань.

E-mail: intechkorm@mail.ru

Ахметзянова Фирая Казбековна - д-р биол. наук, доц., зав. каф. кормления Казанской государственной академии ветеринарной медицины им. Н.Э. Баумана, г. Казань. E-mail: lady.firaya@bk.ru

Крупин Евгений Олегович - канд. ветеринар. наук, зав. отделом агробиологических исследований Татарского НИИ сельского хозяйства - обособленного структурного подразделения ФИЦ «КазНЦ РАН», г. Казань. E-mail: intechkorm@mail.ru

Цель исследования - изучить эфрфективность скармливания энергетической кормовой добавки (ЭКД) «ЦеолФат» молодняку крупного рогатого скота. Задачи: изучить химический состав и питательность ЭКД «ЦеолФат», разработать научно обоснованные рационы для телят с учетом введения в них изучаемой кормовой добавки; определить влияние ЭКД «ЦеолФат» на фиизиологическое состояние, рост и развитие телят; рассчитать экономическую эфффективность введения ЭКД «ЦеолФат» в рационы телят. Научнохозяйственный опыт по изучению эфорективности скармливания "ЦеолФат» проведен на мегасрерме 000 «Агрокомплекс «Ак Барс» Арского района Республики Татарстан. Опыт состоял из подготовительного (15 суток) и учетного (60 суток) периодов. Для проведения
Kashaeva Aliya Rinatovna - Cand. Biol. Sci., Assoc. Prof., Chair of Feeding, Kazan State Academy of Veterinary Medicine named after N. E. Bauman, Kazan. E-mail: aliam_81@mail.ru

Shakirov Shamil Kasymovich - Dr. Agr. Sci., Prof., Chief Staff Scientist, Department of Agrobiological Researches, Tatar Research and Development Institute of Agriculture, Specialized Structural Division, FRC "KasRC RAS", Kazan.

E-mail: intechkorm@mail.ru

Akhmetzyanova Firaya Kazbekovna - Dr. Biol. Sci., Assoc. Prof., Head, Chair of Feeding, Kazan State Academy of Veterinary Medicine named after N. E. Bauman, Kazan. E-mail: lady.firaya@bk.ru Krupin Evgeny Olegovich - Cand. Veterinary Sci., Head, Department of Agrobiological Researches, Tatar Research and Development Institute of Agriculture, Specialized Structural Division, FRC "KasRC RAS", Kazan. E-mail: intechkorm@mail.ru

опыта были отобраны телята голштинизированной черно-пестрой породы в возрасте 2 месяцев со средней живой массой 80 кг и разделены на 3 группы по 10 голов в каждой. Все телята были клинически здоровы. Содержание животных групповое. Разница между группами заключалась в том, что телята контрольной группы получали основной ращион согласно схеме выращивания телок до 6-месячного возраста. Телятам опытных групп скармливали тот же состав кормов, что и контрольным, но с разницей: в I опытной группе взамен аналогичного количества зерновых введена изучаемая кормовая добавка 200 г, II - 300 г на голову в сутки. Введение ЭКД «ЦеолФат» в состав комбикормов для телят увеличивает энергетическую питательность рационов, содержание сырого жира, макро- и микроэле- 
ментов. Способствует повышению среднесуточных приростов живой массы на 22,0-34,8 \% $(P<0,001)$ и снижению затрат кормов на 1 ке прироста живой массы 26,1-33,0 \%. Экономический эфрфект на 1 рубль дополнительных затрат составляет 7,02-7,32 руб.

Ключевые слова: комбикорм, энергия, молодняк крупного рогатого скота, прирост живой массы, экономика.

The purpose of the research was the effectiveness of feeding energy feed additive (EFA) "ZeolFat" to young cattle. The research objectives were to study chemical composition and nutritional value of EFA "ZeolFat", to develop scientifically based diets for calves, taking into account the introduction of studied feed additive; to determine the effect of EFA "ZeolFat" on physiological state, growth and development of calves; to calculate economic efficiency of the introduction of EFA "ZeolFat" in calves' diets. Scientific and economic experiment of studying the effectiveness of feeding "ZeolFat" was made at mega farm of LLC "Agrocomplex "AK Bars" Arsky district of Tatarstan. The experiment consisted of preparatory (15 days) and research (60 days) periods. For the experiment, the calves of Holstinized black-and-motley breed at the age of 2 months with an average live weight of $80 \mathrm{~kg}$ were selected and divided into 3 groups of 10 heads each. All the calves were clinically healthy. The animals were kept in the groups. The difference between the groups was that the calves of the control group received the main diet according to the scheme of growing heifers up to 6 months of age. The calves of experimental groups were fed with the same feed composition as the control ones, but in the 1-st experimental group it slightly differed: every day instead of similar amount of grain, the studied feed additive was given by $200 \mathrm{~g}$, and in the 2-nd - $300 \mathrm{~g}$ a head. Adding EFA "ZeolFat" into the composition of mixed feeds for calves increases energetic nutritional value of the diets, the content of raw fat, macro- and microelements. It helps to increase the average daily gain in body weight by $22.0-34.8 \%(P<0.001)$ and reduced feed costs per $1 \mathrm{~kg}$ of live weight gain 26.1-33.0 \%. Economic effect on 1 ruble of additional costs is 7.02-7.32 rubles.

Keywords: compound feed, energy, young growth of cattle, live weight gain, economy.
Введение. Многочисленные отечественные и зарубежные научные разработки, опыт животноводов-практиков доказывают, что полноценное кормление животных, особенно ремонтного молодняка [1], невозможно без использования кормовых добавок с высоким продуктивным действием. Однако недостатком большинства из них является дефицит не только сырого белка, но и энергии [2]. В настоящее время для решения данной проблемы используются такие кормовые добавки, как сухие пальмовые жиры, пропиленгликоль, глицерин, другие регуляторы углеводного и липидного обмена, которые являются дорогостоящими [3].

Общеизвестно, что для нормального течения процессов роста, развития и продуктивности животным необходимы не только белки, жиры и углеводы, но и минеральные вещества [4]. Основная часть кормов не удовлетворяет потребность животных по минеральным веществам. Десицит суточного потребления макро- и микроэлементов доходит до 70-80 \%. В связи с этим необходим поиск новых доступных и высокоэфффективных кормовых добавок, позволяющих восполнить в рационах животных не только недостающую часть энергии, но и минеральную составляющую рационов.

В свою очередь, восполнению дефицита энергии может способствовать использование отходов масложирового производства. Помимо распространенных отходов (жмыхи, шроты и др.), в отрасли АПК образуется ряд других, не менее ценных видов вторичного сырья [5-7]. Несмотря на объемы и химический состав, сырье утилизируется и загрязняет окружающую среду. Прежде всего это касается возвратных из торговых сетей продуктов питания с истекающим сроком годности, которые уже сегодня могут стать исходным сырьем для получения высококачественных кормов [2].

В этой связи энергетическая кормовая добавка (ЭКД) «ЦеолФат», разработанная сотрудниками отдела агробиологических исследований ТатНИИСХ ФИЦ КазНЦ РАН и кафедры кормления ФГБОУ ВО Казанская ГАВМ, является оригинальной кормовой добавкой, произведенной по научно обоснованному рецепту. «ЦеолФат» состоит из майонеза с массовой долей жира 58,0-67,0 \% с истекающим сроком годности, природного минерала - активированного 
цеолита и антиоксиданта нового поколения Бисфренол-5.

ЭКД «ЦеолФат» получена путем механического смешивания компонентов. Отличительным признаком является то, что в предлагаемом технологическом решении используется цеолит активированный, полученный при высушивании в трехконтурном сушильном барабане при определенном температурном режиме согласно тУ 10.91.10-002-27860096-2017. Обжиг происходит в мягком режиме без разрушения структуры сырья, вследствие которого продукт приобретает новые качества с повышенными адсорбирующими, каталитическими и ионообменными свойствами. Антиоксидант Бисфенол-5 добавлен для защиты жирных кислот от окисления (прогоркания) и активного участия его в обмене веществ.

Цель исследований. Изучить эфффективность скармливания энергетической кормовой добавки «ЦеолФат» молодняку крупного рогатого скота.

Задачи исследований: изучить химический состав и питательность ЭКД «ЦеолФат», разработать научно обоснованные рационы для телят с учетом введения в них изучаемой кормовой добавки; определить влияние ЭКД «ЦеолФат» на физиологическое состояние, рост и развитие телят; рассчитать экономическую эффективность введения ЭКД «ЦеолФат» в рационы телят.

Объекты и методы исследований. Опыт по изучению влияния скармливания «ЦеолФат» на организм телят проведен на мегаферме ООО «Агрокомплекс «Ак Барс» Арского района Рес- публики Татарстан в период со 2 марта по 14 мая 2019 года. Для проведения опыта были отобраны телята голштинизированной чернопестрой породы в возрасте 2 месяцев со средней живой массой 80 кг и разделены на 3 группы по 10 голов в каждой. Все телята были клинически здоровы. Содержание животных групповое.

Опыт состоял из подготовительного (15 суток) и учетного (60 суток) периодов. В подготовительный период был проведен зоотехнический анализ кормов, изучены состав и питательность фактических рационов, осуществлено наблюдение за состоянием здоровья животных. Отбор и оформление средних проб кормов проводили согласно рекомендациям [8]. Рационы и рецепты комбикормов для всех подопытных телят были разработаны с помощью компьютерной программы «Корм Оптима Эксперт».

Условия содержания для всех телят были одинаковыми, кормление животных проводилось в соответствии с зоотехническими нормами [9]. Разница между группами заключалась в том, что телята контрольной группы получали основной рацион согласно схеме выращивания телок до 6-месячного возраста. Телятам опытных групп скармливали тот же состав кормов, что и контрольным, но с разницей: в I опытной группе взамен аналогичного количества зерновых введена изучаемая кормовая добавка 200 г (комбикорм № 2); II - 300 г (комбикорм № 3) на голову в сутки, что в процентном выражении от состава комбикорма составляет 10 и $15 \%$ соответственно (табл. 1).

Таблица 1

\section{Рецептура комбикормов для телят от 2 до 4-месячного возраста}

\begin{tabular}{|l|c|c|c|}
\hline \multirow{2}{*}{ Компоненты, \% } & \multicolumn{3}{c|}{ Комбикорм } \\
\cline { 2 - 4 } & № 1 & № 2 & № 3 \\
\hline \multicolumn{1}{|c|}{1} & 2 & 3 & 4 \\
\hline Ячмень & 20,0 & 20,0 & 20,0 \\
\hline Соя (СП 34 \%) & 20,0 & 20,0 & 20,0 \\
\hline Жмых подсолнечный (СП 36 \%) & 15,0 & 15,0 & 15,0 \\
\hline Кукуруза & 15,0 & 10,0 & 8,2 \\
\hline Пшеница & 12,0 & 10,0 & 10,0 \\
\hline Овес & 10,0 & 8,0 & 5,0 \\
\hline Дрожжи кормовые (СП 38 \%) & 5,0 & 5,0 & 5,0 \\
\hline Монокальцийфоссрат & 1,5 & 0,5 & 0,3 \\
\hline
\end{tabular}




\begin{tabular}{|l|c|c|c|}
\hline \multicolumn{4}{|c|}{ Окончание табл. 1} \\
\hline \multicolumn{1}{|c|}{1} & 2 & 3 & 4 \\
\hline Соль & 0,5 & 0,5 & 0,5 \\
\hline Премикс ПКР-1 & 1,0 & 1,0 & 1,0 \\
\hline ЭКД «ЦеолФат» & - & 10,0 & 15,0 \\
\hline \multicolumn{1}{|l|}{ В 1 кг комбикорма содержится: } \\
\hline ОЭ (обменной энергии), МДж & 11,90 & 12,10 & 12,20 \\
\hline ОЭ (обменной энергии), ЭКЕ & 1,19 & 1,21 & 1,22 \\
\hline СВ (сухого вещества), \% & 88,68 & 88,70 & 88,71 \\
\hline СП (сырого протеина), \% & 21,87 & 21,06 & 20,64 \\
\hline СЖ (сырого жира), \% & 3,76 & 4,88 & 5,78 \\
\hline СК (сырой клетчатки), \% & 6,76 & 5,32 & 4,95 \\
\hline сахара+крахмала, \% & 31,40 & 26,74 & 24,66 \\
\hline кальция, г & 9,50 & 9,80 & 10,70 \\
\hline сросфрора, г & 8,90 & 7,40 & 7,00 \\
\hline магния, г & 2,30 & 2,60 & 2,80 \\
\hline серы, г & 1,30 & 1,30 & 1,30 \\
\hline натрия, г & 2,30 & 2,40 & 2,45 \\
\hline хлора, г & 3,70 & 3,70 & 3,60 \\
\hline железа, мг & 76,13 & 243,60 & 327,10 \\
\hline меди, мг & 9,86 & 9,78 & 9,75 \\
\hline цинка, мг & 70,00 & 70,00 & 70,00 \\
\hline марганца, мг & 36,30 & 33,80 & 32,00 \\
\hline кобальта, мг & 1,00 & 1,00 & 1,00 \\
\hline цода, мг & 2,00 & 2,00 & 2,00 \\
\hline витамина А, тыс. МЕ & 15,0 & 15,0 & 15,0 \\
\hline витамина Д, тыс. МЕ & 25,00 & 25,00 & 25,00 \\
\hline витамина Е, мг & \multicolumn{3}{l|}{} \\
\hline
\end{tabular}

Динамику изменения живой массы животных изучали по результатам индивидуальных взвешиваний ежемесячно утром (до кормления). Экономическую целесообразность рассчитывали согласно «Методике определения экономической эфффективности ветеринарных мероприятий» [10].

При обработке результатов исследований использованы общепринятые методы вариационной статистики на персональном компьютере при помощи программы Microsoft Office Excel 2010 c учетом критерия достоверности по Стьюденту.

Результаты исследований и их обсуждение. Исследованиями установлено, что введение изучаемой кормовой добавки «ЦеолФат» в состав комбикормов увеличило энергетическую питательность рационов телят | и || опытных групп на 1,6 и 2,5 \%, сырого жира на 29,0 и 53,0, кальция на 3,0 и 12,0, магния на 13,0 и $21 \%$, железа в 3,2 и 4,3 раза соответственно (табл. 1). Протеиновая, углеводная и витаминная питательность рационов всех групп соответствовала детализированным нормам кормления телят данной возрастной группы.

Важным показателем эффрективности использования кормов и кормовых добавок является интенсивность роста животных. Установлено, что скармливание ЭКД «ЦеолФат» оказало положительное влияние на динамику прироста живой массы телят. Если в конце учетного периода опыта живая масса телят в контрольной группе увеличилась на 40,34 кг, или 50,1\%, то в І опытной группе увеличение показателя составило 49,21 кг (60,9\%), во II 54,39 кг (67,7\%). Разница в показателе у телят I и || опытных групп по отношению к контрольным составила 8,87 кг, или 21,9\%, и 14,05 кг, или 34,8 \%, соответственно (табл. 2). 
Изменение живой массы телят контрольной и опытных групп

Таблица 2 за период опыта

\begin{tabular}{|c|c|c|c|}
\hline \multirow{2}{*}{ Показатель } & \multicolumn{3}{|c|}{ Группа $(n=10)$} \\
\hline & Контрольная & І опытная & ІІ опытная \\
\hline \multicolumn{4}{|l|}{ Живая масса, кг: } \\
\hline в начале опыта & $80,52 \pm 2,72$ & $80,69 \pm 5,53$ & $80,38 \pm 2,74$ \\
\hline в конце опыта & $120,86 \pm 4,14$ & $129,90 \pm 8,73$ & $134,77 \pm 5,42$ \\
\hline \multicolumn{4}{|l|}{ Прирост живой массы: } \\
\hline валовый, кг & $40,34 \pm 1,80$ & $49,21 \pm 1,30$ & $54,39 \pm 1,50$ \\
\hline разница к контролю \pm , кг & - & $+8,87$ & $+14,05$ \\
\hline среднесуточный, г & $672,3 \pm 11,80$ & $820,2 \pm 10,60^{* * *}$ & $906,5 \pm 10,40^{* * \star}$ \\
\hline разница к контролю \pm , г & - & $+147,90$ & $+234,20$ \\
\hline \multicolumn{4}{|l|}{ Затрачено на 1 кг прироста живой массы: } \\
\hline ОЭ, МДж & 66,07 & 52,40 & 49,67 \\
\hline СП, г & 72,88 & 56,37 & 52,80 \\
\hline $\begin{array}{l}\text { Стоимость комбикорма, руб/кг } \\
\text { В т.ч. ЭКД «ЦеолФат» }\end{array}$ & $\begin{array}{c}20,80 \\
-\end{array}$ & $\begin{array}{c}21,96 \\
2,00\end{array}$ & $\begin{array}{c}22,56 \\
3,00\end{array}$ \\
\hline Стоимость комбикорма на 1 голову в сутки, руб. & 41,60 & 43,92 & 45,12 \\
\hline Разница к контролю \pm , руб. & - & 2,32 & 3,52 \\
\hline Стоимость дополнительного прироста, руб/гол. & - & 16,27 & 25,76 \\
\hline $\begin{array}{l}\text { Экономическая эфффективность на } 1 \text { руб. затрат, } \\
\text { руб. }\end{array}$ & - & 7,02 & 7,32 \\
\hline
\end{tabular}

${ }^{* * *} \mathrm{P}>0,999$.

Среднесуточный прирост за период опытного кормления у телят контрольной группы составил 672,3 г, а в опытных группах соответственно 820,2 и 906,5 г, или на 22,0 и 34,8\% (P<0,001) больше.

Телята опытных групп более экономно расходовали энергию на продукцию. Так, затраты кормов на 1 кг прироста живой массы составили в контрольной группе 66,07 МДж, а у телят I группы 52,4, II группы 49,67 МДж, то есть на 26,1 и 33,0 \% меньше, чем у контрольных. Затраты сырого протеина на 1 кг прироста у телят I и II опытных групп также были ниже по сравнению с контрольными на 22,65 и 27,55 \% соответственно.

При расчете экономической эфффективности выявлено, что стоимость дополнительного прироста составила в I опытной группе 16,27 руб., во II - 25,76 руб. Принимая во внимание себестоимость 1 кг ЭКД «Цеолфат» с учетом дополнительной переработки компонента и смешивания 20 руб., а удорожание суточной нормы комбикорма для телят I группы 2,32, II - 3,52 руб., получим экономический эффрект на 1 рубль дополнительных затрат - 7,02 и 7,32 руб. соответственно.

Выводы. Скармливание телятам с 2 до 4-месячного возраста энергетической кормовой добавки «ЦеолФат» в составе комбикорма способствует повышению энергетической и минеральной питательности рационов, увеличению энергии роста и является экономически целесообразным. Для повышения биологической полноценности рационов и увеличения прироста живой массы ремонтного молодняка рекомендуем вводить в состав комбикормов, начиная с 2-месячного возраста, ЭКД «ЦеолФат» в количестве $10-15 \%$.

\section{Литература}

1. Прытков Ю.Н., Кистина А.А., Дорожкина Е.И. Применение хвойно-энергетической добавки в кормлении молодняка крупного рогатого скота в молочный период выращивания // Аграрный научный журнал. 2019. № 4. С. 60-63.

2. Артемьева О.А., Павлюченкова О.В., Котковская Е.Н. [и др.]. Возможности использования продуктов вторичной переработки для получения кормового белка // Молочное и мясное скотоводство. 2015. № 6. C. $33-35$. 
3. Райхман А.Я. Эфрфективность использования энергетических добавок в рационах лактирующих коров // Мат-лы междунар. науч.практ. конф. Омск. гос. аграр. ун-та им. П.А. Столыпина. Омск, 2016. С. 121-124.

4. Чепелев Н.А., Харламов И.С. Минеральный обмен у коров при использовании хелатных соединений микроэлементов // Вестник Курской государственной сельскохозяйственной академии. 2013. № 9. С. 64-66.

5. Мустафраев С.К., Смьччагин Е.О. Разработка комплексной технологии переработки отходов масложирового производства // Научные труды КубГТУ. 2019. № 3. С. 883-895.

6. Шакиров Ш.К. [и др.]. Ресурсы вторичного сырья - источник энергии в рационах крупного рогатого скота // Кормопроизводство. 2011. № 9. C. 39-42.

7. Ярмоц Г.А., Саткеева А.Б., Ярмоц Л.П. Использование природных кормовых добавок для повышения продуктивности животных // Кормление сельскохозяйственных животных и кормопроизводство. 2016. № 4. С. 16-25.

8. Аликаев В.А., Петухова Е.А., Халенова И.Д. Руководство по контролю качества кормов и полноценности кормления сельскохозяйственных животных. М.: Колос, 1982. $250 \mathrm{C}$.

9. Калашников А.П. [и др.]. Нормы и рационы кормления сельскохозяйственных животных: справ. пособие. 3-е изд., перераб. и доп. М.: Знание, 2003. 456 с.

10. Шатохин Ю.Е. [и др.]. Методика определения экономической эфффективности ветеринарных мероприятий. М.: МГАВМиБ им. К.И. Скрябина, 1997. 36 с.

\section{Literatura}

1. Prytkov Ju.N., Kistina A.A., Dorozhkina E.I. Primenenie hvojno-jenergeticheskoj dobavki v kormlenii molodnjaka krupnogo rogatogo skota
V molochnyj period vyrashhivanija // Agrarnyj nauchnyj zhurnal. 2019. № 4. S. 60-63.

2. Artem'eva O.A., Pavljuchenkova O.V., Kotkovskaja E.N. [i dr.]. Vozmozhnosti ispol'zovanija produktov vtorichnoj pererabotki dlja poluchenija kormovogo belka // Molochnoe i mjasnoe skotovodstvo. 2015. № 6. S. 33-35.

3. Rajhman A.Ja. Jeffektivnost' ispol'zovanija jenergeticheskih dobavok $v$ racionah laktirujushhih korov // Mat-ly mezhdunar. nauch.-prakt. konf. Omsk. gos. agrar. un-ta im. P.A. Stolypina. Omsk, 2016. S. 121-124.

4. Chepelev N.A., Harlamov I.S. Mineral'nyj obmen u korov pri ispol'zovanii helatnyh soedinenij mikrojelementov // Vestnik Kurskoj gosudarstvennoj sel'skohozjajstvennoj akademii. 2013. № 9. S. 64-66.

5. Mustafaev S.K., Smychagin E.O. Razrabotka kompleksnoj tehnologii pererabotki othodov maslozhirovogo proizvodstva // Nauchnye trudy KubGTU. 2019. № 3. S. 883-895.

6. Shakirov Sh.K. [i dr.]. Resursy vtorichnogo syr'ja - istochnik jenergii v racionah krupnogo rogatogo skota // Kormoproizvodstvo. 2011. № 9. S. 39-42.

7. Jarmoc G.A., Satkeeva A.B., Jarmoc L.P. Ispol'zovanie prirodnyh kormovyh dobavok dlja povyshenija produktivnosti zhivotnyh // Kormlenie sel'skohozjajstvennyh zhivotnyh i kormoproizvodstvo. 2016. № 4. S. 16-25.

8. Alikaev V.A., Petuhova E.A., Halenova I.D. Rukovodstvo po kontrolju kachestva kormov i polnocennosti kormlenija sel'skohozjajstvennyh zhivotnyh. M.: Kolos, 1982. $250 \mathrm{~s}$.

9. Kalashnikov A.P. [i dr.]. Normy i raciony kormlenija sel'skohozjajstvennyh zhivotnyh: sprav. posobie. 3-e izd., pererab. i dop. M.: Znanie, 2003. $456 \mathrm{~s}$.

10. Shatohin Ju.E. [i dr.]. Metodika opredelenija jekonomicheskoj jeffektivnosti veterinarnyh meroprijatij. M.: MGAVMiB im. K.I. Skrjabina, 1997. $36 \mathrm{~s}$. 